\title{
Cell density influences antibiotic biosynthesis in Streptomyces clavuligerus
}

\author{
L. Sánchez and A. F. Braña \\ Author for correspondence: A. F. Braña. Tel: +34 8 5104217. Fax: + 3485103534.
}

Area de Microbiología, Departamento de Biología Funcional, Instituto Universitario de

Biotecnología de Asturias, Facultad de Medicina, Universidad de Oviedo, 33006 Oviedo, Spain

\begin{abstract}
Production of cephamycin C and clavulanic acid by Streptomyces clavuligerus took place during the exponential phase of growth in a defined medium. Both antibiotic biosynthetic pathways were activated shortly after spore germination, but the timing and kinetics of activation were affected by inoculum density. Rapid activation was favoured by high inoculum density or by growth in medium conditioned by previous incubation of $\mathbf{S}$. clavuligerus spores or mycelium. A heat-resistant conditioning factor able to accelerate the acquisition of antibiotic-biosynthetic capacity when added to low-density cultures was released in suspensions of spores in water. Conditioning factor was also obtained in suspensions of spores from different Streptomyces species or of Bacillus cells, indicating that the signal was not produced specifically by $S$. clavuligerus. Fractionation of conditioning factor showed that its effect was not due to a single molecule. The fractions contained amino acids (as free amino acids and oligopeptides) in amounts that roughly correlated with their respective conditioning power. Furthermore, the conditioning effect was reproduced by supplementing defined medium with amino acids and peptides in concentrations that mimicked those found in conditioning factor. When individually tested at concentrations in the micromolar range, only some amino acids were able to stimulate antibiotic biosynthetic capacity. This stimulation was also promoted by low concentrations (less than $1 \mu \mathrm{g} \mathrm{ml}^{-1}$ ) of peptide mixtures obtained with different proteolytic enzymes. The results suggest that both amino acids and peptides are responsible for the effects of conditioning factor released by spores. Possible implications of intercellular signalling on activation of secondary metabolism are discussed.
\end{abstract}

Keywords: Streptomyces clavuligerus, cell density, antibiotic biosynthesis, cephamycin C, clavulanic acid

\section{INTRODUCTION}

Members of the bacterial genus Streptomyces are characterized by their great ability to produce a variety of secondary metabolites, many of them with antibiotic activity. The biosynthetic routes leading to the formation of these compounds are regulated in a complex manner, and at least two levels of control seem to operate in all cases. The activation of a given pathway is influenced mainly by the nature and concentration of the carbon, nitrogen and phosphorous sources, occurring only under a particular range of nutritional conditions. Sub-optimal growth caused by a more or less severe limitation in the nutrient supply favours the biosynthesis of most secondary metabolites (Martin \& Demain, 1980). This type of control is highly specific for every strain and even for every secondary metabolite produced by a given strain (Bushell \& Fryday, 1983; Hobbs et al., 1990). In the best known cases, the products encoded by pathway-specific regulatory genes activate the corresponding biosynthetic genes (Malpartida \& Hopwood, 1986; Anzai et al., 1987; Piepersberg et al., 1988; Narva \& Feitelson, 1990; Geistlich et al., 1992; Stutzman-Engwall et al., 1992), but the way in which information (nutritional or of some other nature) is transmitted to these regulatory genes is unknown.

A second level of control is suggested by the observation that single mutations can lead to the simultaneous loss of different secondary metabolic activities. This loss, observed in many species of Streptomyces, is often accompanied by deficiencies in morphological differentiation, a pheno- 
type that is readily detected on agar plates. Vegetative growth, that is, primary metabolism, remains unaltered in these mutants. In the best-characterized species, Streptomyces coelicolor, many bld mutants impaired in morphological differentiation and secondary metabolism have been isolated, although their phenotypes are usually conditional, depending on medium composition (Chater, 1993). Other $S$. coelicolor mutants retain the ability to differentiate, but they have different pleiotropic defects in secondary metabolism. The known loci involved in these phenotypes include abs $A$ and $a b s B$ (Champness et al., 1992), aba A (Fernández Moreno et al., 1992), afsR/afsK (Horinouchi \& Beppu, 1992a), and afsQ1/afsQ2 (Ishizuka et al., 1992). Pleiotropic control in other Streptomyces may be exerted by related mechanisms, since sequences homologous to some of these genes have been detected in other species (Fernández Moreno et al., 1992; Ishizuka et al., 1992; Matsumoto et al., 1994). Among bacteria other than Streptomyces, the existence of genes that pleiotropically control secondary metabolism activities is known at least in Bacillus (Marahiel et al., 1993) and Pseudomonas (Laville et al., 1992).

A situation in which different metabolic pathways coded by physically unlinked groups of genes share a common regulatory mechanism is typical of global regulatory networks (Neidhardt et al., 1990). The fact that secondary metabolism (or at least groups of activities belonging to it) is organized in that way, has some important consequences. First of all, it implies that it is not a mere collection of properties that are arbitrarily grouped because they are not essential for growth. A global regulation indicates that the individual activities included in the network have a common physiological meaning, a meaning that may not be obvious when they are considered individually. This mode of regulation also implies that the master genes that control the network must receive some signal that would determine whether the network is activated or not. To this initiating signal other specific signals should follow that, acting on the pathway specific regulators, would determine the degree of expression of the different secondary metabolic activities under pleiotropic control.

Using Streptomyces clavuligerus, we have tried to identify a hypothetical signal involved in the switching on of secondary metabolism. The ability of this strain to produce two antibiotics, cephamycin $\mathrm{C}$ and clavulanic acid, was used as a metabolic indicator. These antibiotics are synthesized by independent pathways and their production can be dissociated under appropriate conditions (Romero et al., 1984). Nevertheless, among mutants selected for inability to produce cephamycin $\mathrm{C}$ it is common to find pleiotropic mutants that simultaneously lose clavulanic acid production (unpublished results), which suggests that both pathways share a common control. In a previous work (Bascarán et al., 1991), we tested the hypothesis of the stringent response (ppGpp) as an initiating signal. The results obtained were not consistent with such hypothesis, although they suggested the involvement of some ribosome-related function in the pleiotropic control. In this work we have tried to asses the possible role of intercellular signalling on the activation of secondary metabolism. This is a type of regulatory mechanism which is being implicated in a growing number of microbial activities (Kaiser \& Losick, 1993; Fuqua et al., 1994), including the control of particular biosynthetic pathways belonging to secondary metabolism (Horinouchi \& Beppu, 1992b).

\section{METHODS}

Bacterial strain and culture conditions. $S$. clavuligerus NRRL, 3585 (ATCC 27064) was used in this study. Spores of this microorganism were obtained on plates with sporulation medium that contained $\left(\mathrm{g} \mathrm{l}^{-1}\right)$ : MOPS, 21 ; glucose, 5 ; yeast extract, $0 \cdot 5$; meat extract, 0.5 ; enzymic hydrolysate of casein, 1 ; agar, $20 . \mathrm{pH}$ was adjusted to $7 \cdot 0$ before autoclaving. Plates were inoculated with lyophilized mycelium to obtain confluent growth. After $5 \mathrm{~d}$ incubation at $28{ }^{\circ} \mathrm{C}$, spores were scraped off with a plastic spatula and suspended in distilled water. The suspensions were sonicated in an ultrasonic bath for $4 \mathrm{~min}$, washed four times with water, resuspended in a small volume of $25 \%$ glycerol in $33 \mathrm{mM}$ MOPS pH 6.8 , and stored in aliquots at $-70^{\circ} \mathrm{C}$. The liquid medium used for growth was based on the synthetic MF medium (Bascarán et al., 1991) to which $0 \cdot 2 \%(\mathrm{w} / \mathrm{v})$ sodium fumarate and $20 \mathrm{mM} \mathrm{NH}_{4} \mathrm{Cl}$ were added (MFFN medium). This medium was sterilized by filtration through polysulfone membranes $(0.2 \mu \mathrm{m}$ pore size). The concentration of the MOPS buffer included in the medium varied according to the maximal cell density reached in the corresponding experiment, measured as $\mathrm{OD}_{600}: 10 \mathrm{mM}$ for $\mathrm{OD}_{600}$ values lower than $1.0 ; 33 \mathrm{mM}$ when $\mathrm{OD}_{600}$ was between 1.0 and $2 \cdot 0 ; 100 \mathrm{mM}$ for cultures grown to $\mathrm{OD}_{600}>2.0$ (Kontron Uvicon 930 spectrophotometer). Supplements were added to the filtered medium as concentrated solutions in $0 \cdot 1 \mathrm{M} \mathrm{HCl}$. Liquid cultures were inoculated as follows: an aliquot of a concentrated frozen suspension of spores was thawed in a water bath at $37{ }^{\circ} \mathrm{C}$ for $3 \mathrm{~min}$, washed once with water and added to the medium to obtain the desired cell density. One $\mathrm{OD}_{600}$ unit was equivalent to $1.9 \times 10^{8}$ c.f.u. $\mathrm{ml}^{-1}$ in the spore suspensions (determined on trypticase soy agar after $3 \mathrm{~d}$ incubation). With mycelium, 1 $\mathrm{OD}_{600}$ unit was equivalent to $0.25 \mathrm{mg}$ dry weight $\mathrm{ml}^{-1}$. Cultures were incubated in an orbital shaker at $30^{\circ} \mathrm{C}$ and 250 r.p.m., using Erlenmeyer flasks with a volume of medium not higher than $20 \%$ of the capacity of the flask. For long-term preservation and as an inoculum for production of spores, mycelium growing in trypticase soy broth was lyophilized in the presence of $20 \%$ (w/v) skimmed milk.

Antibiotic biosynthetic capacity. The functioning of the cephamycin $\mathrm{C}$ and clavulanic acid biosynthetic pathways was determined in vivo, using concentrated suspensions of washed cells. A volume of culture containing approximately $1 \mathrm{mg}$ dry weight cells was filtered through a polysulfone membrane (25 mm diameter, $0.2 \mu \mathrm{m}$ pore size), washed three times with $5 \mathrm{ml}$ water and the filter with the cells was placed in a flatbottomed glass vial ( $25 \mathrm{~mm}$ bottom diameter) containing $400 \mu \mathrm{l}$ MF medium supplemented with $100 \mu \mathrm{g}$ chloramphenicol $\mathrm{ml}^{-1}$. The cells were resuspended by vigorous vortexing, the filter was removed and the vial was incubated in an orbital shaker at $30^{\circ} \mathrm{C}$ and 400 r.p.m. After $2 \mathrm{~h}$, the cells were eliminated by centrifugation and the antibiotics produced were determined in the supernatant. In these conditions, accumulation of cephamycin $\mathrm{C}$ was linear with time, even for incubations longer than $3 \mathrm{~h}$, whereas that of clavulanic acid decayed gradually after $90 \mathrm{~min}$. The biosynthetic capacity of the cells was expressed as units of antibiotic produced in $2 \mathrm{~h}(\mathrm{mg} \text { cell dry } \mathrm{wt})^{-1}$ under the above conditions. 

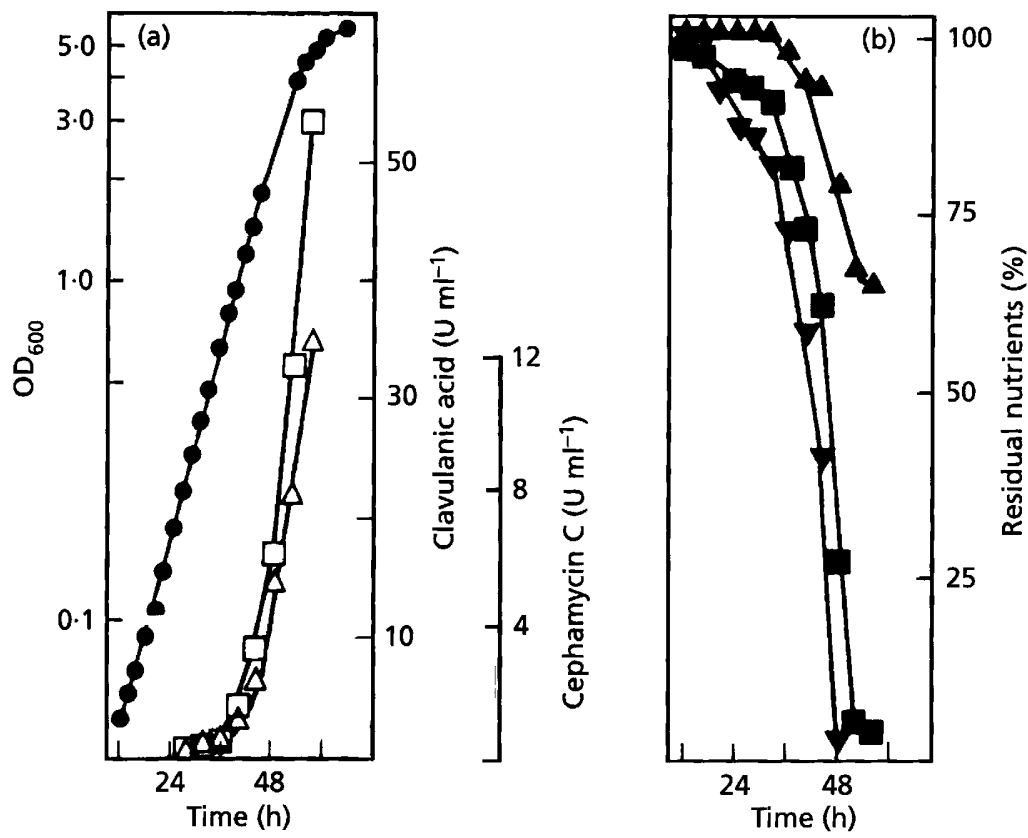

Fig. 1. Growth, antibiotic production and nutrient consumption in MFFN medium. Spores were used as inoculum to give an initial $O_{600}$ of 0.04 . (a) Growth as $O D_{600}(0)$ and accumulation of cephamycin $C(\triangle)$ and clavulanic acid ( $\square$ ). (b) Residual levels of glycerol $(\boldsymbol{\Delta})$, fumarate $(\boldsymbol{\nabla})$ and ammonium $(\square)$ in the culture medium.
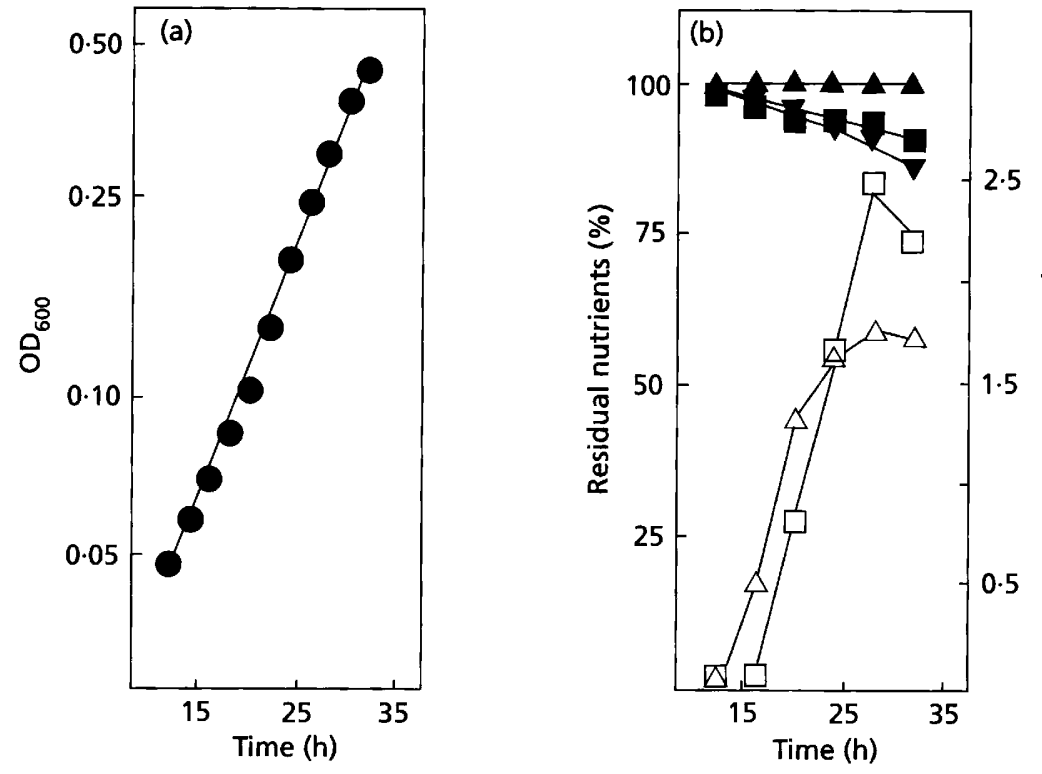

Fig. 2. Activation of antibiotic biosynthetic pathways. MFFN medium was inoculated with spores at an initial $O D_{600}$ of 0.04 . (a) Growth as $O D_{600}(O)$. (b) Cephamycin $C(\triangle)$ and clavulanic acid ( $\square$ ) biosynthetic capacity. Residual levels of glycerol ( $\boldsymbol{\Delta})$, fumarate $(\boldsymbol{\nabla})$ and ammonium $(\boldsymbol{\nabla})$ in the culture medium.

Antibiotic assays. Clavulanic acid was determined by HPLC after derivatization with imidazole, according to Foulstone \& Reading (1982). Derivatized samples $(25 \mu \mathrm{l})$ were chromatographed in a $\mu$ Bondapak $\mathrm{C} 18$ column $(3.9 \times 300 \mathrm{~mm}$; Waters $)$ with methanol:0.1 $\mathrm{M} \mathrm{KH}_{2} \mathrm{PO}_{4}, \mathrm{pH} 3 \cdot 2,(12: 88)$ as the mobile phase, at a flow rate of $2 \mathrm{ml} \mathrm{min}^{-1}$. Detection was at $318 \mathrm{~nm}$ and calibration was performed with solutions of clavulanic acid (a gift from Antibioticos). One unit of antibiotic was defined as the equivalent to $1 \mu \mathrm{g}$ clavulanic acid. The same chromatography column was used for cephamycin $\mathrm{C}$ determinations. Samples

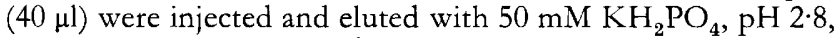
at a flow rate of $2 \mathrm{ml} \mathrm{min}^{-1}$. The $\mathrm{pH}$ of the buffer was acidified gradually (down to $\mathrm{pH} 2 \cdot 4$ ) as the column aged. Cephamycin $\mathrm{C}$ was detected as an isolated peak with a retention time close to $10 \mathrm{~min}$. Method development and calibration was carried out with pure cephamycin $\mathrm{C}$ isolated from $S$. clavuligerus cultures (see below). Samples of cephamycin C were determined by HPLC and integration values were correlated with their respective potency measured by bioassay (Braña et al., 1985). One unit of cephamycin $\mathrm{C}$ was defined as the amount of antibiotic producing an inhibition zone equivalent to $1 \mu \mathrm{g}$ cephalosporin $\mathrm{C}$ in the bioassay.

Isolation of cephamycin C. A stationary phase culture in MF medium with $15 \mathrm{mM}$ asparagine was centrifuged and the supernatant was lyophilized. The dried material was extracted with $70 \%$ ethanol at $4{ }^{\circ} \mathrm{C}$ and the insoluble residue was eliminated by centrifugation (O'Sullivan et al., 1979). The supernatant was evaporated and the residue was redisolved in a small volume of water and chromatographed in a $\mu$ Bondapak C18 column with $20 \mathrm{mM}$ ammonium acetate $\mathrm{pH} 5.5$ as the 
mobile phase, at a flow rate of $2 \mathrm{ml} \mathrm{min}^{-1}$. Fractions with antibiotic activity were pooled, lyophilized, redissolved in water and chromatographed in the same column with $2 \%$ methanol in water acidified to $\mathrm{pH} 3.0$ with formic acid, at a flow rate of $2 \mathrm{ml}$ $\min ^{-1}$. A major peak with antibiotic activity and spectral characteristics of cephamycin C (Nagarajan et al., 1971) was detected. The material in this peak was collected in multiple injections, lyophilized and stored at $-20^{\circ} \mathrm{C}$.

Production of peptide mixtures. Electrophoretically homogeneous BSA was partially hydrolysed with trypsin, proteinase $\mathrm{K}$ or pronase (Boehringer). In the three cases, $0.3 \mathrm{~g}$ albumin in $100 \mathrm{ml} 5 \mathrm{mM}$ MOPS $\mathrm{pH} 7.5$ was treated with $10 \mathrm{mg}$ protease for $30 \mathrm{~min}$ at $37^{\circ} \mathrm{C}$. The enzymes were inactivated at $100^{\circ} \mathrm{C}$ during $15 \mathrm{~min}$ and the reaction products were lyophilized and stored at $-70^{\circ} \mathrm{C}$.

Analytical methods. Colorimetric methods were used for determination of residual glycerol (Bok \& Demain, 1977) and ammonium (Weatherburn, 1967) in the culture medium. Residual fumaric acid was measured by HPLC, using a $\mu$ Bondapak C18 column and $0 \cdot 1 \mathrm{M} \mathrm{KH}_{2} \mathrm{PO}_{4} \mathrm{pH} 3 \cdot 2$ at $2 \mathrm{ml} \mathrm{min}^{-1}$ as the mobile phase, with detection at $214 \mathrm{~nm}$. Protein concentrations were determined by the method of Bradford (1976). Amino acids were determined by HPLC after derivatization with $\mathrm{O}$ phthaldialdehyde (Hill et al., 1979). Total amino acids in conditioning factor were measured by the same method following previous hydrolysis with $6 \mathrm{M} \mathrm{HCl}$ at $110^{\circ} \mathrm{C}$ during 24 h. HPLC fractionation of conditioning factor was performed in a $\mu$ Bondapak C18 column using a linear gradient from $100 \%$ of $0.1 \%(\mathrm{v} / \mathrm{v})$ trifluoroacetic acid in water to $100 \%$ of $0.1 \%$ $(\mathrm{v} / \mathrm{v})$ trifluoroacetic acid in acetonitrile in $30 \mathrm{~min}$, at a flow rate of $0.8 \mathrm{ml} \mathrm{min} \mathrm{m}^{-1}$.

Reproducibility of results. All the experiments shown were repeated at least three times, except the one described in Table 1 , which was done once with all strains. Although the phenomena described in this paper were completely reproducible, the absolute values concerning antibiotic biosynthetic activities and potency of conditioning solutions varied somewhat between experiments, depending on the lot of spores used. In the course of the work this problem was minimized by a careful control of the age of the sporulating cultures and the procedures to isolate the spores. As a consequence, representative results are shown in all tables and figures, except for Fig. 3 (three independent experiments are shown) and Table 5 (mean of three independent experiments).

\section{RESULTS}

\section{Initiation of secondary metabolism in MFFN medium}

Germination of spores in MFFN medium began to be observed after $4 \mathrm{~h}$ incubation. Although germination was not synchronous and a substantial part of the spores germinated at later times, exponential growth was established by approximately $10 \mathrm{~h}$, after a drop in the initial $\mathrm{OD}_{600}$. Cultures grew with an initial doubling time of about $6 \mathrm{~h}$, reaching stationary phase at an $\mathrm{OD}_{600}$ close to 6.0 (Fig. 1a). The two carbon sources were used simultaneously, with preferential utilization of fumarate. By the time the nitrogen source was exhausted, a large amount of residual glycerol was still present in the medium (Fig. 1b). Phosphate concentration was in large excess (initially $20 \mathrm{mM}$ ). Accumulation of cephamycin $\mathrm{C}$ and clavulanic acid occurred in parallel with growth (Fig. 1a). However, due to the low biomass during early stages
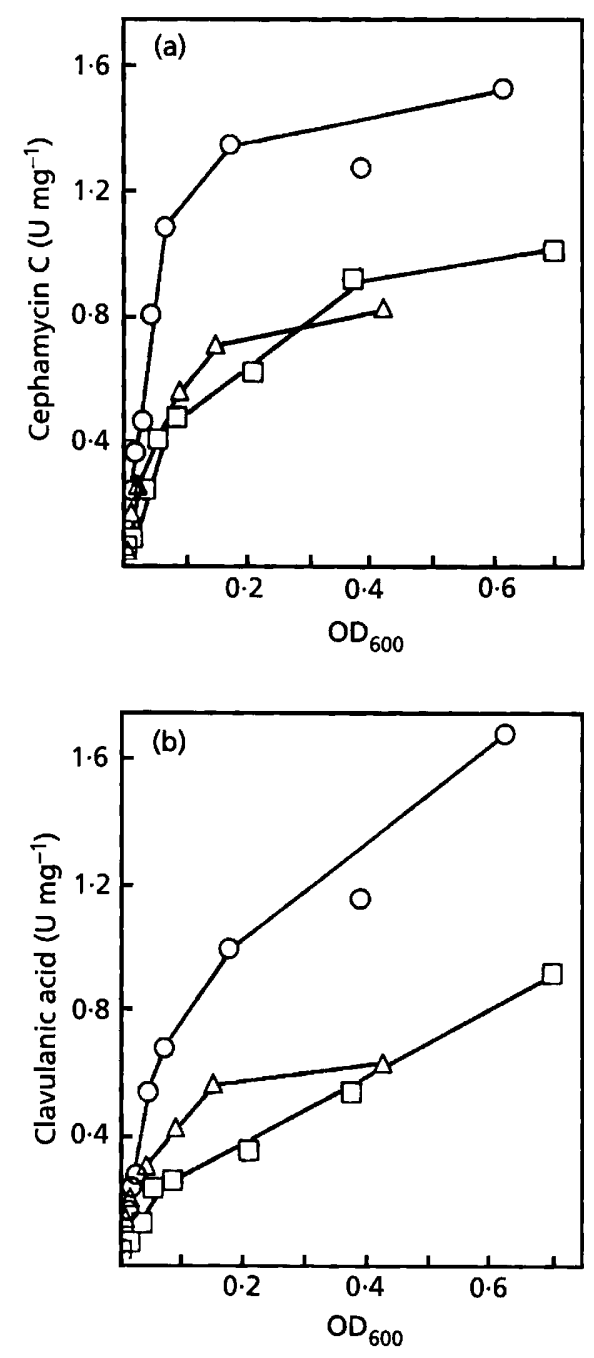

Fig. 3. Cephamycin $C$ (a) and clavulanic acid (b) biosynthetic capacity as a function of cell density. Flasks with MFFN medium were inoculated with spores at different cell densities. After incubation for $17 \mathrm{~h}$ the antibiotic biosynthetic capacity of the cells in each culture was measured. The different symbols represent the values obtained in three independent experiments with different batches of spores, plotted against the corresponding $\mathrm{OD}_{600}$ of the cultures at the time of harvesting.

of growth, measurements of antibiotic in the culture medium were not a useful indicator of the functioning of antibiotic biosynthetic pathways in that period. This was determined by using concentrated cell suspensions, as described in Methods. A detailed experiment showing the activation of the antibiotic biosynthetic pathways is shown in Fig. 2. Both pathways were activated rapidly during the early exponential phase of growth, while carbon and nitrogen sources remained above $85 \%$ of the initial values. No clumping of the mycelia was observed during this period of activation.

To test whether cell density had any relationship with the activation, an experiment was designed in which several flasks with MFFN medium were inoculated with different 


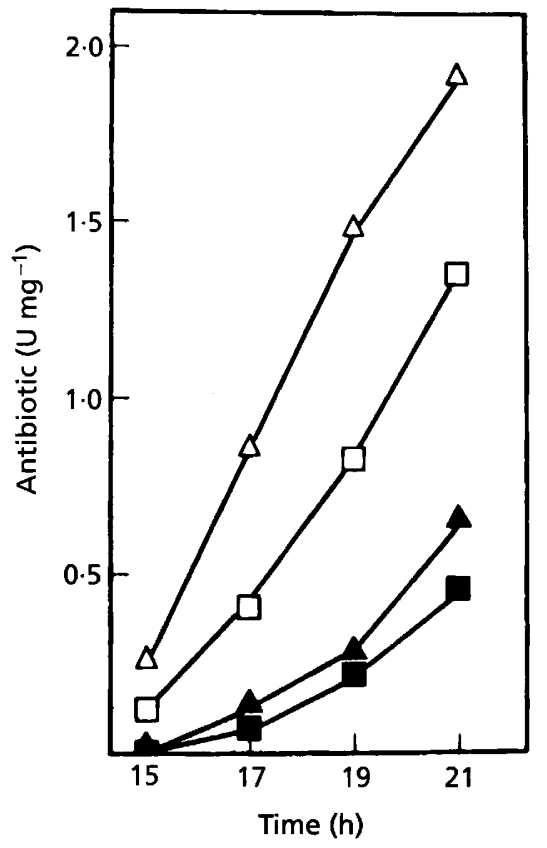

Fig. 4. Kinetics of activation of antibiotic biosynthetic pathways as a function of initial cell density. MFFN medium was inoculated with spores at an initial $O_{600}$ of $0.0025(A, \square)$ or 0.04 $(\triangle, \square)$. The cultures were sampled at intervals to measure their cephamycin $C(\Delta, \Delta)$ and clavulanic acid $(\square, \square)$ biosynthetic capacity.

amounts of spores and incubated for a fixed time $(17 \mathrm{~h})$ before their respective antibiotic synthesizing capacities were measured. In Fig. 3 we show the results of three independent experiments of this type in which, in spite of differences between batches of spores, it is evident that high cell density favoured the activation of both pathways. In some experiments, a slight stimulation of growth was observed in flasks receiving high inocula (initial $\mathrm{OD}_{600}$ above $0 \cdot 05$ ). The strongest differences in activity occurred within a range of very low cell densities, where nutritional effects are not expected. A similar dependence on cell density was found in experiments inoculated with different amounts of stationary phase mycelium (data not shown). A time-course experiment comparing cultures with two initial spore densities is shown in Fig. 4. A remarkable difference in the timing and kinetics of activation, which occurred earlier and faster in the cultures that received higher inocula, was observed.

\section{Conditioned cultures}

The differences observed in the latter experiments could have been caused by the release of activating molecules into the culture medium. This possibility was tested as follows: conditioned media were prepared by inoculating spores at different densities in MFFN medium; after a $17 \mathrm{~h}$ incubation, the cells were removed by filtration and the filter-sterilized media were re-inoculated with spores at a low density $\left(\mathrm{OD}_{600}=0 \cdot 005\right)$. The antibiotic biosynthetic capacity in these cultures was stimulated in a

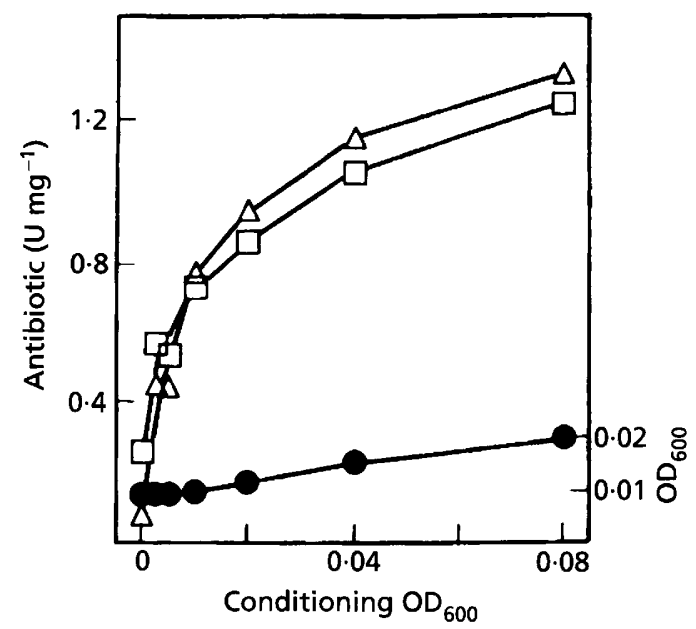

Fig. 5. Activation of antibiotic biosynthetic pathways in media conditioned by previous incubation with $S$. clavuligerus spores. Flasks with MFFN medium were inoculated with spores at different densities and incubated during $17 \mathrm{~h}$. The microorganism was removed by filtration and the media were filtersterilized and re-inoculated with spores at a low density $\left(O D_{600}=0.005\right)$. After further incubation for $17 \mathrm{~h}$ the cephamycin $C(\triangle)$ and clavulanic acid $(\square)$ biosynthetic capacity as well as $O D_{600}(\Theta)$ were determined in each culture. In the figure these values are plotted against the initial $O_{600}$ used for conditioning, the zero value corresponding to a nonconditioned control culture.

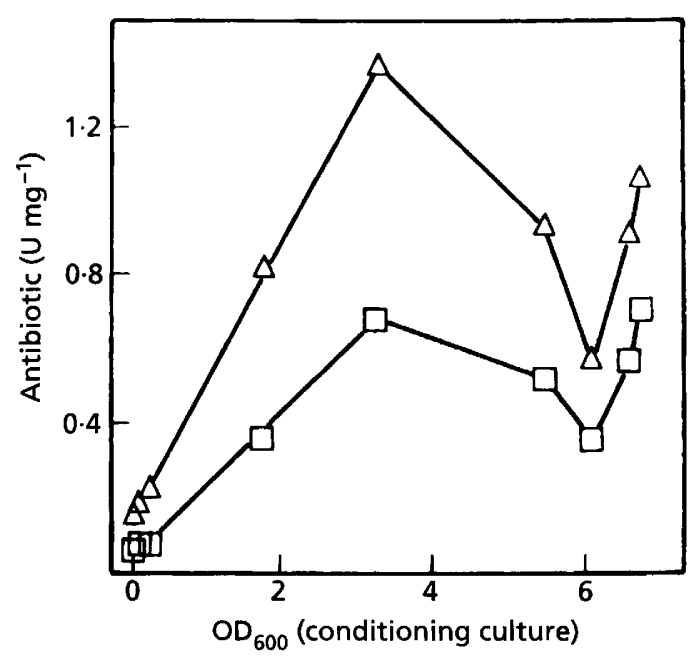

Fig. 6. Activation of antibiotic biosynthetic pathways in media conditioned with $S$. clavuligerus mycelium. A flask with MFFN medium was inoculated with stationary phase mycelium (initial $O D_{600}=0.04$ ). Growth of this culture was monitored and, at intervals, fractions were taken and filter-sterilized. Ten millilitres of each filtrate were added to flasks with $400 \mathrm{ml}$ fresh MFFN medium that were inoculated with spores at a low density $\left(O D_{600}=0.005\right)$. After $17 \mathrm{~h}$ incubation, the cephamycin $C(\triangle)$ and clavulanic acid $(\square)$ biosynthetic capacity of the cells in each culture were determined. The values are plotted against the $\mathrm{OD}_{600}$ of the conditioning culture at the moment the respective fraction was taken, the zero value corresponding to a non-conditioned control culture. 
Table 1. Obtention of conditioning factor with different micro-organisms

Spores of Streptomyces species were obtained on plates with sporulation medium incubated for $5 \mathrm{~d}$, as described in Methods for $S$. clavuligerus. Unicellular bacteria were grown on plates with sporulation medium during $3 \mathrm{~d}$ at $30^{\circ} \mathrm{C}$, scraped off with a plastic spatula, suspended in distilled water and washed three times with water. Washed cells of every strain were incubated in water $\left(\mathrm{OD}_{600}=5.0\right)$ at $30^{\circ} \mathrm{C}$ and 250 r.p.m. After $8 \mathrm{~h}$, cells were removed by centrifugation and the supernatants were sterilized by filtration. The conditioning power of the solutions obtained was tested by adding $1.8 \mathrm{ml}$ each solution to $400 \mathrm{ml}$ MFFN medium. The resulting media were inoculated with spores at a low density $\left(\mathrm{OD}_{600}=\right.$ $0.005)$ and the antibiotic biosynthetic capacities were determined after $17 \mathrm{~h}$ incubation.

\begin{tabular}{|lcc|}
\hline Micro-organism & \multicolumn{2}{c|}{ Biosynthetic capacity $\left(\mathbf{U ~ m g ~}^{\mathbf{- 1}}\right)^{*}$} \\
\cline { 2 - 3 } & Cephamycin C & Clavulanic acid \\
\hline Streptomyces albus G & $0 \cdot 27$ & $0 \cdot 18$ \\
Streptomyces antibioticus ATCC 11891 & $0 \cdot 44$ & $0 \cdot 23$ \\
Streptomyces carpinensis ATCC 27116 & $0 \cdot 19$ & $0 \cdot 12$ \\
Streptomyces clavuligerus & $1 \cdot 24$ & $0 \cdot 99$ \\
Streptomyces coelicolor A3(2) & $0 \cdot 29$ & $0 \cdot 11$ \\
Streptomyces lividans J1326 & $1 \cdot 09$ & $0 \cdot 65$ \\
Bacillus cereus ATCC 9139 & $0 \cdot 32$ & $0 \cdot 16$ \\
Bacillus subtilis BD 630 & $0 \cdot 62$ & $0 \cdot 27$ \\
Escherichia coli TG 1 & $0 \cdot 17$ & $0 \cdot 11$ \\
Micrococcus luteus ATCC 4698 & $0 \cdot 15$ & $0 \cdot 09$ \\
\hline
\end{tabular}

*The biosynthetic capacities obtained in a non-conditioned control culture were $0 \cdot 12 \mathrm{U} \mathrm{mg}^{-1}$ for cephamycin $\mathrm{C}$ and $0.09 \mathrm{U} \mathrm{mg}^{-1}$ for clavulanic acid.

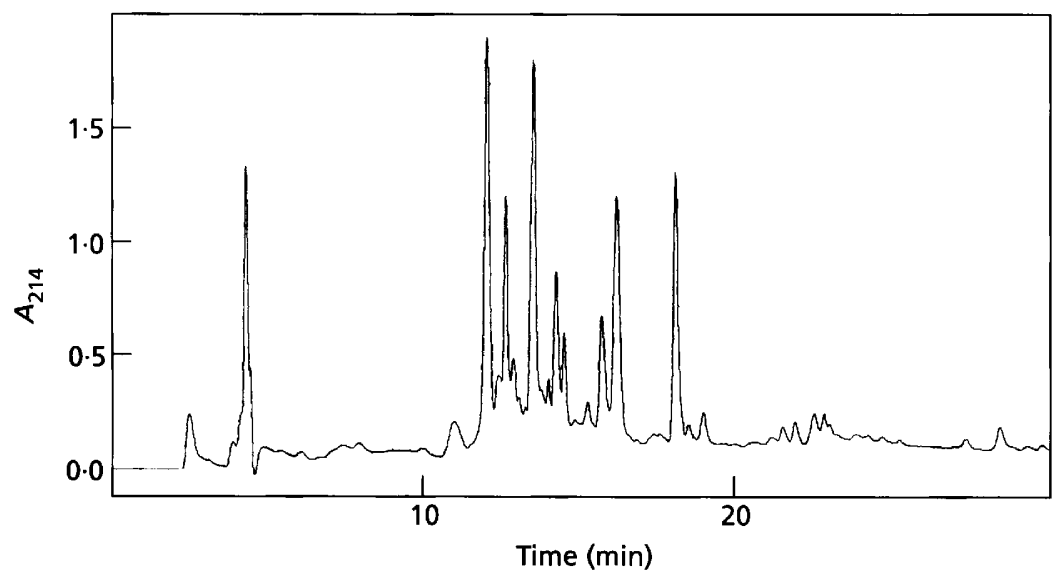

Fig. 7. HPLC analysis of a $150 \mu$ injection of concentrated conditioning solution prepared as described in the text. way proportional to the spore density used for conditioning (Fig. 5). A slight stimulation of growth was also apparent in the cultures conditioned with high spore densities. A slight reduction in the initial concentrations of fumarate, $\mathrm{NH}_{4} \mathrm{Cl}$ and glycerol to the residual levels measured in medium conditioned with a high spore density $\left(\mathrm{OD}_{600}=0.3\right)$, did not affect antibiotic biosynthetic capacity. These experiments indicated that some extracellular factor able to activate secondary metabolism was released from the spores and accumulated in a cell density dependent fashion. In medium inoculated with spores at $\mathrm{OD}_{600}=0 \cdot 04$, a $1 \mathrm{~h}$ incubation was enough to detect stimulation in the antibiotic biosynthetic capacity of spores inoculated later at a low density. Longer incubations of the conditioning spores caused increasing stimulations, indicating that the conditioning factor was released gradually from the spores. A mild heat-treatment $\left(63{ }^{\circ} \mathrm{C}, 10 \mathrm{~min}\right)$ that killed $94 \%$ of the spores did not destroy their ability to release the conditioning factor, which accumulated at an even higher rate over an $8 \mathrm{~h}$ period, indicating that spore germination was not required for its formation and/or release. Furthermore, spores obtained on solid MFFN medium also had conditioning activity when tested in the same way. This eliminates the possibility that compounds from the complex sporulation medium would have been responsible for the effects as contaminants of the spore suspensions. In fact, the production of conditioning factor was 
Table 2. Analysis of conditioning factor after HPLC fractionation

Fractions were collected every $5 \mathrm{~min}$ and numbered consecutively: $1,0-5 \mathrm{~min} ; 2,5-10 \mathrm{~min} ; 3$, 10-15 min; 4, 15-20 min; 5, 20-25 min; 6, 25-30 min. Five hundred microlitres of each concentrated fraction were added to flasks with $400 \mathrm{ml}$ MFFN medium. These, together with an unsupplemented control, were inoculated with spores at an initial $\mathrm{OD}_{600}$ of $0 \cdot 005$.

\begin{tabular}{|c|c|c|c|c|c|}
\hline Fraction & $\begin{array}{l}\text { Cephamycin } \\
\mathrm{C}^{*}\left(\mathrm{U} \mathrm{mg}^{-1}\right)\end{array}$ & $\begin{array}{c}\text { Clavulanic } \\
\text { acid* }\left(\mathrm{U}^{\mathrm{mg}} \mathrm{mg}^{-1}\right)\end{array}$ & $\begin{array}{c}\text { Free amino } \\
\text { acids } \dagger \\
\left(\mathrm{nmol} \mathrm{ml}^{-1}\right)\end{array}$ & $\begin{array}{c}\text { Total amino } \\
\text { acids } \ddagger \\
\left(\mathrm{nmol} \mathrm{ml}^{-1}\right)\end{array}$ & $\begin{array}{c}\text { Protein } \begin{array}{c}\text { (ng } \\
\left.\mathrm{ml}^{-1}\right)\end{array}\end{array}$ \\
\hline Control & $0 \cdot 10$ & 0.04 & - & - & - \\
\hline 1 & 1.00 & $0 \cdot 42$ & $2 \cdot 50$ & $3 \cdot 66$ & $<0.1$ \\
\hline 2 & $0 \cdot 31$ & $0 \cdot 13$ & $0 \cdot 16$ & 0.65 & $<0.1$ \\
\hline 3 & 0.58 & $0 \cdot 24$ & $0 \cdot 77$ & 3.57 & $<0 \cdot 1$ \\
\hline 4 & 0.61 & $0 \cdot 34$ & $0 \cdot 16$ & 1.67 & $2 \cdot 0$ \\
\hline 5 & $0 \cdot 28$ & $0 \cdot 13$ & $<0 \cdot 01$ & 0.44 & $14 \cdot 5$ \\
\hline 6 & $0 \cdot 25$ & $0 \cdot 10$ & $<0.01$ & 0.43 & $10 \cdot 2$ \\
\hline
\end{tabular}

* Antibiotic biosynthetic capacities measured after $17 \mathrm{~h}$ incubation in cultures supplemented with the respective fraction.

† Concentration in conditioned medium calculated from the values obtained by analysis of concentrated fractions. The sum of concentrations of each amino acid is given. Proline and cysteine, which are not detected by the method used, are not included.

$\ddagger$ Same as $\dagger$, but determined after acid hydrolysis of concentrated fractions.

\section{Table 3. Amino acids content in conditioned medium}

Values were calculated after addition of $1 \mathrm{ml}$ concentrated conditioning solution to $400 \mathrm{ml}$ MFFN medium.

\begin{tabular}{|c|c|c|}
\hline \multirow[t]{2}{*}{ Amino acid } & \multicolumn{2}{|c|}{$\begin{array}{l}\text { Concentration in conditioned medium } \\
\qquad(\mathrm{nM})\end{array}$} \\
\hline & Free amino acids* & Total amino acids \\
\hline Alanine & $369 \cdot 1$ & $1872 \cdot 5$ \\
\hline Arginine & $44 \cdot 2$ & $512 \cdot 5$ \\
\hline Asparagine & $8 \cdot 9$ & - \\
\hline Aspartate & $5 \cdot 4$ & $1001 \cdot 2$ \\
\hline Glutamate & $126 \cdot 2$ & $1531 \cdot 8$ \\
\hline Glycine & $60 \cdot 6$ & $475 \cdot 5$ \\
\hline Histidine & - & $153 \cdot 6$ \\
\hline Isoleucine & $2 \cdot 8$ & $345 \cdot 9$ \\
\hline Leucine & 166.9 & $814 \cdot 0$ \\
\hline Lysine & $53 \cdot 1$ & $310 \cdot 2$ \\
\hline Methionine & $31 \cdot 4$ & $138 \cdot 5$ \\
\hline Phenylalanine & $35 \cdot 7$ & $255 \cdot 8$ \\
\hline Serine & $6 \cdot 8$ & $433 \cdot 0$ \\
\hline Threonine & $91 \cdot 0$ & $581 \cdot 2$ \\
\hline Tryptophan & $8 \cdot 5$ & - \\
\hline Tyrosine & $29 \cdot 8$ & $137 \cdot 9$ \\
\hline Valine & $151 \cdot 8$ & $949 \cdot 8$ \\
\hline
\end{tabular}

* Determined in untreated conditioning solution.

† Determined in conditioning solution after acid hydrolysis.

also detected during growth of $S$. clavuligerus mycelium in liquid MFFN medium (Fig. 6). In this case, the conditioning power of the medium increased in samples taken during the logarithmic phase of growth, declined in later stages and increased again in samples from stationary phase. As the conditioning culture in this experiment had been inoculated with stationary phase mycelium, it implied that the release of conditioning factor was not an exclusive property of spores. Attempts to obtain conditioning compounds by liquid extraction of conditioned medium with ethyl acetate or chloroform at different $\mathrm{pH}$ values were unsuccessful.

It was found that concentrated $\left(\mathrm{OD}_{600}=5 \cdot 0\right)$ suspensions of spores in water also released conditioning factor (detected upon addition to medium inoculated at a low cell density), an observation that was exploited for an easier characterization of the responsible compounds. Washed substrate and aerial mycelium obtained from cellophane-covered solid sporulation medium also produced conditioning factor when incubated in water for $8 \mathrm{~h}$. This, together with the above experiment with mycelium in liquid MFFN medium, indicated that the release of the factor was not associated with a particular phase of the Streptomyces developmental cycle. An attempt was made to obtain conditioning factor from other bacteria. As shown in Table 1, when incubated in water, spores of different Streptomyces species released compounds able to activate secondary metabolism in $S$. clavuligerus to different degrees. Among unicellular bacteria tested, a significant conditioning power was obtained in suspensions of Bacillus, B. subtilis in particular.

\section{Identification of conditioning compounds}

We tried to identify compounds responsible for the conditioning activity produced by concentrated suspensions of spores in water. This conditioning activity was 
Table 4. Stimulation of antibiotic biosynthetic capacities with conditioning solution or with amino acids or peptides at equivalent concentrations

The indicated supplements were added to $400 \mathrm{ml}$ MFFN medium. The resulting media were inoculated with spores (initial $\mathrm{OD}_{600}=0.005$ ) and the antibiotic biosynthetic capacities were measured after incubation for $17 \mathrm{~h}$. Amino acid composition of the conditioning solution employed is shown in Table 3.

\begin{tabular}{|c|c|c|}
\hline \multirow[t]{2}{*}{ Supplement } & \multicolumn{2}{|c|}{ Biosynthetic capacity $\left(\mathrm{U} \mathrm{mg}^{-1}\right)$} \\
\hline & Cephamycin $\mathrm{C}$ & Clavulanic acid \\
\hline Control & $0 \cdot 07$ & $0 \cdot 04$ \\
\hline Conditioning solution* & 0.70 & $0 \cdot 49$ \\
\hline Hydrolysed conditioning solution $\dagger$ & $0 \cdot 76$ & $0 \cdot 54$ \\
\hline Free amino acids $\ddagger$ & $0 \cdot 20$ & $0 \cdot 14$ \\
\hline Total amino acids $₫$ & 0.53 & $0 \cdot 30$ \\
\hline Albumin hydrolysate\| & $0 \cdot 76$ & $0 \cdot 51$ \\
\hline
\end{tabular}

* $1 \mathrm{ml}$ conditioning solution.

$\dagger 1 \mathrm{ml}$ conditioning solution after acid hydrolysis.

$¥$ Amino acids added at concentrations mimicking free amino acids in $1 \mathrm{ml}$ conditioning solution.

\Amino acids added at concentrations mimicking total amino acids in $1 \mathrm{ml}$ conditioning solution.

\| Albumin hydrolysate obtained with pronase was added at $1.18 \mu \mathrm{g} \mathrm{ml}^{-1}$, equivalent (by weight) to total amino acids in $1 \mathrm{ml}$ conditioning solution.

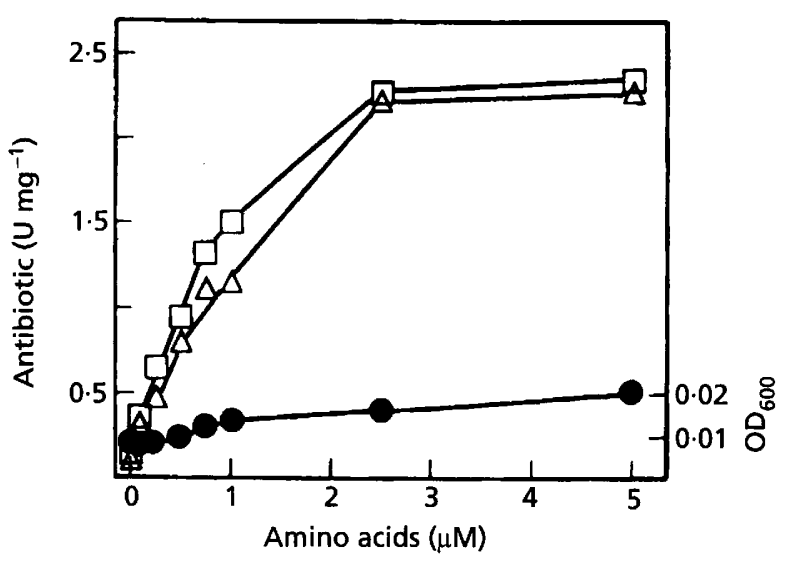

Fig. 8. Effect of an amino acid mixture on activation of antibiotic biosynthetic capacity. MFFN medium was supplemented with different concentrations of a mixture of 19 common amino acids (without cysteine). Media were inoculated with spores at a low density $\left(O D_{600}=0.005\right)$ and, after $17 \mathrm{~h}$ incubation, the cephamycin $C(\triangle)$ and clavulanic acid $(\square)$ biosynthetic capacity as well as $\mathrm{OD}_{600}(\boldsymbol{Q})$ were determined. The values are plotted against the corresponding concentration of each amino acid in the medium.

heat-stable $\left(100^{\circ} \mathrm{C}, 10 \mathrm{~min}\right)$ and, after lyophilization, most of the activity could be recovered by extraction with either water or methanol. In order to identify the compound or compounds involved, we fractionated solutions with conditioning activity and searched for the presence of amino acids and peptides, some of which are known to function in intercellular signalling in other micro-organisms (Kaiser \& Losick, 1993). Thirty millilitres of conditioning solution were obtained by incubating spores $\left(\mathrm{OD}_{600}=5 \cdot 0\right)$ in water at $30^{\circ} \mathrm{C}$ for $8 \mathrm{~h}$. After removal of cells by centrifugation, the solution was lyophilized and the residue was redissolved in $2 \mathrm{ml}$ water. Fig. 7 shows the result of HPLC analysis of the concentrated conditioning solution. A total of $1.5 \mathrm{ml}$ of this solution was chromatographed (10 injections of $150 \mu \mathrm{l})$ and six fractions of $4 \mathrm{ml}$ were collected on each run. The corresponding fractions from the different injections were pooled, the solvents were evaporated and the residues were redissolved in $1 \mathrm{ml}$ water. The contents of free amino acids, total amino acids and protein, as well as the conditioning power, were analysed for each concentrated fraction. As shown in Table 2, the conditioning power was distributed unevenly along the different fractions. The higher activities corresponded to the fractions that contained higher amounts of total amino acids. Most free amino acids eluted in the first fraction, but a substantial amount of amino acids was released by acid hydrolysis in all fractions. Since the fractions contained material absorbing at $214 \mathrm{~nm}$, most of which was not detected by the protein assay and was not strongly retained by the reversed-phase column, the latter amino acids are likely to arise from hydrolysis of oligopeptides. A similar distribution of the conditioning activity was found when the lyophylized conditioning solution was redissolved in methanol prior to HPLC analysis or after fractionation of a conditioning solution obtained with $B$. subtilis cells.

A series of experiments were conducted with controlled addition of amino acids and peptides to verify their possible involvement in the activation of secondary 
Table 5. Effect of amino acids on activation of biosynthetic capacity

Amino acids were added to $400 \mathrm{ml}$ MFFN medium at $10 \mu \mathrm{M}$. Media were inoculated with spores (initial $\mathrm{OD}_{600}=0.005$ ) and incubated for $17 \mathrm{~h}$ before measuring antibiotic biosynthetic capacities.

\begin{tabular}{|c|c|c|}
\hline \multirow[t]{2}{*}{ Amino acid } & \multicolumn{2}{|c|}{ Biosynthetic capacity (\%)* } \\
\hline & Cephamycin C & Clavulanic acid \\
\hline $\mathbf{L}-\alpha$-Aminoadipate & 99 & 103 \\
\hline$\gamma$-Aminobutyrate & 130 & 121 \\
\hline L-Alanine & 138 & 113 \\
\hline L-Arginine & 79 & 99 \\
\hline L-Asparagine & 103 & 102 \\
\hline L-Aspartate & 113 & 111 \\
\hline L-Citrulline & 95 & 106 \\
\hline L-Cysteine & 38 & 35 \\
\hline DL-Diaminopimelate & 97 & 96 \\
\hline L-Glutamate & 119 & 96 \\
\hline L-Glutamine & 103 & 109 \\
\hline Glycine & 294 & 281 \\
\hline L-Histidine & 97 & 105 \\
\hline L-Isoleucine & 327 & 281 \\
\hline L-Leucine & 312 & 246 \\
\hline L-Lysine & 199 & 312 \\
\hline L-Methionine & 145 & 188 \\
\hline L-Phenylalanine & 343 & 178 \\
\hline L-Proline & 75 & 121 \\
\hline L-Serine & 77 & 120 \\
\hline L-Threonine & 206 & 271 \\
\hline L-Tryptophan & 230 & 190 \\
\hline L-Tyrosine & 141 & 120 \\
\hline L-Valine & 203 & 164 \\
\hline
\end{tabular}

* Antibiotic biosynthetic capacities are expressed as percentages of the values obtained in unsupplemented control cultures. These values were $0.18 \mathrm{U} \mathrm{mg}^{-1}$ for cephamycin $\mathrm{C}$ and $0.19 \mathrm{U} \mathrm{mg}^{-1}$ for clavulanic acid (mean of four cultures), with a standard deviation of $\pm 25 \%$ of the mean.

metabolism. A conditioning solution ( $50 \mathrm{ml}$; obtained as above) was lyophilized and the residue was redissolved in $5 \mathrm{ml}$ water and filtered. One half of this concentrated solution was submitted to acid hydrolysis, lyophilized and resuspended in $2.5 \mathrm{ml}$ water. Amino acids were determined in the untreated solution (free amino acids) and in the hydrolysed one (total amino acids). Most peaks were identified as common amino acids, and their concentrations are shown in Table 3, expressed as values in media supplemented with $1 \mathrm{ml}$ each solution. The stimulation of antibiotic biosynthetic activities obtained with the conditioning solution was barely affected by the acid hydrolysis (Table 4). A slight stimulation was observed in medium supplemented with amino acids in concentrations mimicking those of free amino acids in conditioned medium, but supplementation with concentrations similar to those obtained with hydrolysed conditioning solution produced an effect close to that obtained in conditioned
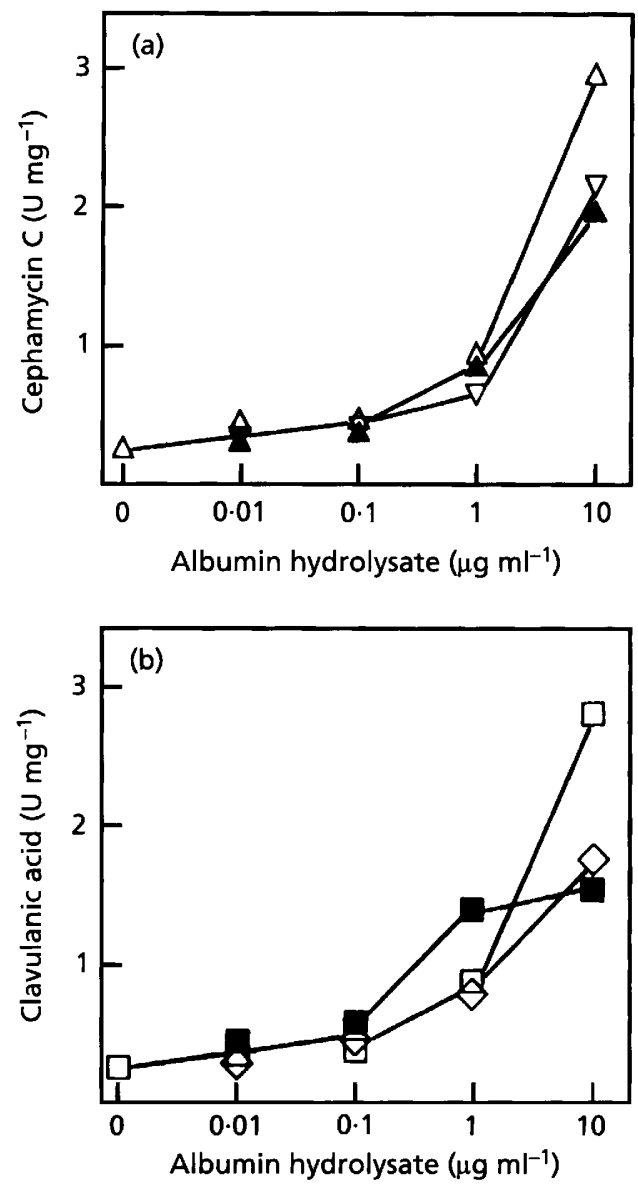

Fig. 9. Effect of enzymic hydrolysates of albumin on activation of antibiotic biosynthetic capacity. MFFN medium was supplemented with the indicated concentration of hydrolysates, inoculated with spores at an $\mathrm{OD}_{600}$ of 0.005 and incubated for $17 \mathrm{~h}$ before measuring activities. The zero values correspond to a non-supplemented control culture. (a) Cephamycin C biosynthetic capacities in media with albumin hydrolysates obtained with proteinase $K(\Delta)$, trypsin $(\nabla)$, or pronase $(\boldsymbol{\Delta})$. (b) Clavulanic acid biosynthetic capacities in media with albumin hydrolysates obtained with proteinase $K(\square)$, trypsin $(\diamond)$ or pronase (a).

medium. This was best mimicked by supplementation with a mixture of amino acids and peptides supplied as an albumin hydrolysate obtained with pronase, added at a concentration equivalent (by weight) to the total amino acids in conditioned medium (Table 4 ). When a mixture of 19 amino acids (without cysteine) was added to MFFN medium, antibiotic biosynthetic pathways were activated in a concentration-dependent mode (Fig. 8). The effect was noticeable at a concentration as low as $100 \mathrm{nM}$, while growth was slightly stimulated when the amino acid mixture was added at $500 \mathrm{nM}$ or higher. When the amino acids were individually tested in the same way at a concentration of $10 \mu \mathrm{M}$, the results indicated that only part of them were effective to several degrees (Table 5). A study of the effect of concentration with one of the most 
effective amino acids, leucine, showed a threshold activating concentration of $100 \mathrm{nM}$, while growth was slightly stimulated at concentrations of $10 \mu \mathrm{M}$ or higher (data not shown). Addition of albumin to MFFN medium did not affect activation of secondary metabolism in low density cultures of $S$. clavuligerus. However, when the medium was supplemented with increasing amounts of enzymic hydrolysates of albumin, a concentration-dependent activation was found (Fig. 9). The effect could not be attributed to a specific peptide since the peptide mixtures were obtained with three different proteolytic enzymes, and different fractions, resulting from separation of peptides from the tryptic hydrolysate by reversedphase HPLC, activated antibiotic biosynthesis (data not shown).

\section{DISCUSSION}

To study the possible involvement of extracellular signals in the initiation of secondary metabolism, we had first to design a medium that would fulfil a series of requirements: (i) a simple chemical composition, excluding organic compounds that might have a signalling function; (ii) to allow the use of spores as inoculum, which would ensure an inactive secondary metabolism in initial conditions and facilitate dispersed growth; (iii) to provide nutritional conditions compatible with full expression of the antibiotic biosynthetic pathways used as indicators of secondary metabolism, thus allowing the recognition of any previous pleiotropic control. The addition of fumarate and $\mathrm{NH}_{4} \mathrm{Cl}$ to the previously used $\mathrm{MF}$ medium resulted in a new medium that complied satisfactorily with these requirements. Powerful analytical techniques were also developed in order to have a high sensitivity in the estimations of the antibiotics produced in concentrated cell suspensions in the presence of chloramphenicol. These estimations constitute an unequivocal indicator of the functioning of antibiotic biosynthetic pathways which, in the case of cephamycin $C$, have been found to correlate with the levels of different enzymes in the pathway (Braña et al., 1985; Bascarán et al., 1991).

The results obtained in this work indicated that the ability of the cells to produce cephamycin $C$ and clavulanic acid can be acquired early after spore germination, without significant changes in the nutrients of the medium. However, switch-on of secondary metabolism did not occur in a constitutive way, but it was influenced by the concentration of spores used as inoculum. This cooperative behaviour was shown to be due to the release of compounds into the medium, which caused an accelerated acquisition of the secondary metabolic traits studied. The effect cannot simply be explained by differences in germination of the spores, since equivalent increases in $\mathrm{OD}_{600}$ were recorded in most cases in unsupplemented cultures. Furthermore, the dependence on cell density for activation was also observed in experiments inoculated with stationary phase mycelium. In conditioned cultures or in media supplemented with amino acids or peptides the respective threshold concentrations for activation of antibiotic biosynthesis were lower than those for stimulation of growth.
There is an increasing recognition of the involvement of intercellular communication in the regulation of many processes in bacteria (Kaiser \& Losick, 1993; Fuqua et al., 1994). In some cases, the manifestation of particular properties is only possible when a certain bacterial population is attained. This is achieved through the release of diffusible factors that accumulate in the medium and are sensed by the bacteria as indicators of cell density. In Streptomyces, intercellular communication appears to play a role in the formation of several secondary metabolites and, sometimes, in triggering morphological differentiation. Accumulation of a threshold level of a low-molecular-mass diffusible compound is needed before some processes of this type can be activated, which may be interpreted as a requirement for a critical cell density. A group of substances widely distributed in actinomycetes and known as autoregulators are needed to activate definite secondary metabolic pathways in the strains that possess them, in a rather specific way (Horinouchi \& Beppu, 1992b). Another manifestation of intercellular communication could be a complex cascade of extracellular signals that appear to be involved in the regulation of morphological differentiation in $S$. coelicolor (Willey et al., 1993). In our case, production of conditioning factor was not restricted to any particular phase in the Streptomyces life-cycle and was detected also with other species, including Bacillus strains, indicating that the production of the signal is not Streptomyces-specific. The relativly higher conditioning activity obtained with $S$. clavuligerus should not be taken as indicative of specificity, since the amount of signal produced was variable between experiments, and no attempt was made to optimize its production with the different micro-organisms. HPLC fractionation of conditioning factor from $S$. clavuligerus or $B$. subtilis also showed that the signal, unlike the case of autoregulators, is composed of different molecules (not less than six in each case), most of which are not highly hydrophobic. Conventional extraction procedures with ethyl acetate or chloroform failed to reveal the presence of activating molecules of the autoregulator type. All this indirect evidence does not completely rule out the possible involvement of this class of compounds, but other results offer a reasonable alternative explanation for the nature of the conditioning factor.

The analysis of fractions obtained from conditioning factor as well as the experiments performed in media with amino acids and peptides indicates that both types of compounds are responsible for most, if not all, of the activating effect. Free amino acids appear to make a minor contribution, but the peptide fraction, which accounts for most of the amino acid content in conditioning factor, seems to be the main active component, as judged from the experiments with media supplemented with amino acids or peptides in amounts mimicking conditioned medium. Small peptides are known to be involved in regulation of some processes by intercellular communication in several bacteria. In some cases, such as conjugal plasmid transfer in Enterococcus faecalis (Clewell, 1993) or developing of competence in B. subtilis (Magnuson et al., 1994), a specific peptide is used as a signal. In others, such 
as transformation efficiency in Streptococcus pneumoniae (Pearce et al., 1994) or sporulation efficiency in B. subtilis (Grossman \& Losick, 1988; Perego et al., 1991; Rudner et al., 1991), the effects have not been attributed to a single peptide species. Our results indicate that different peptides are part of the conditioning factor mediating activation in S. clavuligerus. This complex signal resembles the case of heat-stable A-factor, a mixture of amino acids and peptides that has been proposed to specify the minimum cell density required for the initiation of fruiting body development in Myxococcus xanthus (Kuspa et al., 1992a, b). As in $M$. xantbus, not all amino acids are active, and there are even coincidences in some of those with higher activity in both micro-organisms (leucine, isoleucine, phenylalanine and tryptophan) and in the inhibitory effect of cysteine. The fact that the activity of conditioning factor produced by spores of $S$. clavuligerus was not reduced after destruction of peptides by acid hydrolysis argues that, as suggested for $M$. xantbus (Kuspa et al., 1992b), amino acids may represent the primary signal, and peptides would contribute as a source of free amino acids.

An interesting question is whether there is a threshold cell density to allow initiation, which would mean an absolute requirement for extracellular signalling, as is the case with M. xanthus (Kuspa et al., 1992b). Within the range of initial densities assayed in this work, initiation took place in all cases, but the timing and kinetics of activation were greatly affected. Working at lower densities, besides the technical difficulties of handling very large volumes of culture, would not answer the question due to the filamentous nature of Streptomyces: hyphal growth would eventually lead to high local densities, irrespective of the global density of the culture. The isolation of mutants impaired in the formation of the signal but able to respond to it should be useful in elucidating this question. Preliminary results indicate that the activating effect of extracellular signals is not restricted to the antibiotic pathways studied in this work. The ability of $S$. clavuligerus to synthesize extracellular protease (which shares a pleiotropic control with cephamycin C) (Bascarán et al., 1991) and alkaline phosphatase activities appears to be similarly influenced by cell density (unpublished results). Cell-density-dependent control of all these activities provides a rational regulatory linkage that may apply to other secondary metabolites. As a general rule, secondary metabolites are exported products whose function, whatever it is, is exerted in the surrounding environment. For the product to be effective, a threshold concentration would be required in every case, and this would not be easily reached unless a certain microbial density was involved in production. The simplest way to guarantee this density before the micro-organism engages in costly biosynthetic activities of this type, that otherwise could be of little benefit, would be a mechanism coupling initiation of these activities to cell concentration. This would be a pleiotropic control preceding specific regulation of particular activities. From this point of view, the activities controlled in this way would be social properties, not individual properties, which is coherent with the nonessential character of secondary metabolites. The fact that filamentous micro-organisms (actinomycetes and moulds), that are necessarily social, have a particularly rich secondary metabolism, may also be significant. The possibility that amino acids and peptides may function as indicators of biological activity, denoting the presence of competitors or prey, constitute an alternative explanation that is compatible with the former hypothesis. On the other hand, given the nature of the molecules identified as signals in this work, it is also conceivable that what the pleiotropic mechanism recognizes is amino acid availability for biosynthesis. This nutritional control would be influenced by the composition of the culture medium and by the culture density to the extent that it affects the level of amino acids in the medium. In any case, it would be interesting to test whether these observations may apply to other streptomycetes and whether any of the pleiotropic genes already known are involved in sensing this type of extracellular signal.

\section{ACKNOWLEDGEMENTS}

This work was supported by a grant from the Spanish Ministry of Education and Science, BIO90-0197.

\section{REFERENCES}

Anzai, H., Murakami, T., Imai, S., Satah, A., Nagaoka, K. \& Thompson, C. J. (1987). 'Transcriptional regulation of bialaphos biosynthesis in Streptomyces bygroscopicus. J Bacteriol 169, 3482-3488.

Bascarán, V., Sánchez, L., Hardisson, C. \& Braña, A. F. (1991). Stringent response and initiation of secondary metabolism in Streptomyces clavuligerus. J Gen Microbiol 137, 1625 1634.

Bok, S. H. \& Demain, A. L. (1977). An improved assay for polyols. Anal Biochem 81, 18-20.

Bradford, M. M. (1976). A rapid and sensitive method for the quantitation of microgram quantities of protein utilizing the principle of protein-dye binding. Anal Biochem 72, 248-254.

Braña, A. F., Wolfe, S. \& Demain, A. L. (1985). Ammonium tepression of cephalosporin production by Streptomyces clavuligerus. Can J Microbiol 31, 736-743.

Bushell, M. E. \& Fryday, A. (1983). The application of materials balancing to the characterization of sequential secondary metabolite formation in Streptomyces cattleya NRRL 8057. J Gen Microbiol 129, $1733-1741$.

Champness, W., Riggle, P., Adamidis, T. \& Vandervere, P. (1992). Identification of Streptomyces coelicolor genes involved in regulation of antibiotic biosynthesis. Gene 115, 55-60.

Chater, K. F. (1993). Genetics of differentiation in Streptomyces. Annu Rev Microbiol 47, 685-713.

Clewell, D. B. (1993). Bacterial sex pheromone-induced plasmid transfer. Cell 73, 9 12 .

Fernández Moreno, M. A., Martín Triana, A. J., Martínez, E., Niemi, J., Kieser, H. M., Hopwood, D. A. \& Malpartida, F. (1992). aba $A$, a new pleiotropic regulatory locus for antibiotic production in Streptomyces coelicolor. J Bacteriol 174, 2958 2967.

Foulstone, M. \& Reading, C. (1982). Assay for amoxicillin and clavulanic acid, the components of augmentin, in biological fluids with high performance liquid chromatography. Antimicrob Agents Chemother 22, 753-762. 
Fuqua, W. C., Winans, S. C. \& Greenberg, E. P. (1994). Quorum sensing in bacteria: the LuxR-LuxI family of cell density-responsive transcriptional regulators. J Bacteriol 176, 269-275.

Geistlich, M., Losick, R., Turner, J.R. \& Rao, R. N. (1992). Characterization of a novel regulatory gene governing the expression of a polyketide synthase gene in Streptomyces ambofaciens. Mol Microbiol 6, 2019-2029.

Grossman, A. D. \& Losick. R. (1988). Extracellular control of spore formation in Bacillus subtilis. Proc Natl Acad Sci US A 85, 4369-4373.

Hill, D. W., Walters, F. M., Wilson, D. \& Stuart, J. D. (1979). High performance liquid chromatographic determination of amino acids in the picomole range. Anal Chem 51, 1338-1341.

Hobbs, G., Frazer, C. M., Gardner, D. C. J., Flett, F. \& Oliver, S. G. (1990). Pigmented antibiotic production by Streptomyces coelicolor A3(2): kinetics and the influence of nutrients. J Gen Microbiol 136, 2291-2296.

Horinouchi, S. \& Beppu, T. (1992a). Regulation of secondary metabolism and cell differentiation in Streptomyces: A-factor as a microbial hormone and the AfsR protein as a component of a twocomponent regulatory system. Gene 115, 167-172.

Horinouchi, S. \& Beppu, T. (1992b). Autoregulatory factors and communication in actinomycetes. Annu Rev Microbiol 46, 377-398.

Ishizuka, H., Horinouchi, S., Kieser, H. M., Hopwood, D. A. \& Beppu, T. (1992). A putative two-component regulatory system involved in secondary metabolism in Streptomyces spp. $J$ Bacteriol 174, 7585-7594.

Kaiser, D. \& Losick, R. (1993). How and why bacteria talk to each other. Cell 73, 873-885.

Kuspa, A., Plamann, L. \& Kaiser, D. (1992a). Identification of heatstable A-factor from Myxococcus xantbus. J Bacteriol 174, 3319-3326.

Kuspa, A., Plamann, L. \& Kaiser, D. (1992b). A-signalling and the cell density requirement for Myxococcus xantbus development. $J$ Bacteriol 174, 7360-7369.

Laville, J., Voisard, C., Keel, C., Maurhofer, M., Défago, G. \& Haas, D. (1992). Global control in Pseudomonas fuorescens mediating antibiotic synthesis and suppression of black root rot of tobacco. Proc Natl Acad Sci US A 89, 1562-1566.

Magnuson, R., Solomon, J. \& Grossman, A. D. (1994). Biochemical and genetic characterization of a competence pheromone from B. subtilis. Cell 77, 207-216.

Malpartida, F. \& Hopwood, D. A. (1986). Physical and genetic characterization of the gene cluster for the antibiotic actinorhodin in Streptomyces coelicolor. Mol Gen Genet 205, 66-73.

Marahiel, M. A., Nakano, M. M. \& Zuber, P. (1993). Regulation of peptide antibiotic production in Bacillus. Mol Microbiol 7, 631-636.

Martín, J. F. \& Demain, A. L. (1980). Control of antibiotic synthesis. Microbiol Rev 44, 230-251.
Matsumoto, A., Hong, S.-K., Ishizuka, H., Horinouchi, S. \& Beppu, T. (1994). Phosphorylation of the AfsR protein involved in secondary metabolism in Streptomyces species by a eukaryotic-type protein kinase. Gene 146, 47-56.

Nagarajan, R., Boeck, L. D., Gorman, M., Hamill, R. L., Higgens, C. E., Hoehn, M. M., Stark, W. M. \& Whitney, J. G. (1971). $\beta$ Lactam antibiotics from Streptomyces. J Am Chem Soc 93, 2308-2310.

Narva, K. E. \& Feitelson, J. S. (1990). Nucleotide sequence and transcriptional analysis of the redD locus of Streptomyces coelicolor A3(2). J Bacteriol 172, 326-333.

Neidhardt, F. C., Ingraham, J. L. \& Schaechter, M. (1990). Pbysiology of the Bacterial Cell: a Molecular Approach. Sunderland, MA : Sinauer Associates.

O'Sullivan, J., Aplin, R. T., Stevens, C. M. \& Abraham, E. P. (1979). Biosynthesis of a 7- $\alpha$-methoxycephalosporin. Incorporation of molecular oxygen. Biochem J 179, 47-52.

Pearce, B. J., Naughton, A. M. \& Masure, H. R. (1994). Peptide permeases modulate transformation in Streptococcus pneumoniae. Mol Microbiol 12, 881-892.

Perego, M., Higgins, C. F., Pearce, S. R., Gallagher, M. P. \& Hoch, J. A. (1991). The oligopeptide transport system of Bacillus subtilis plays a role in the initiation of sporulation. Mol Microbiol 5, 173-185.

Piepersberg, W., Distler, J., Ebert, A., Heinzel, P., Mansouri, K., Mayer, G. \& Pissowotzki, K. (1988). Expression of genes for streptomycin biosynthesis. In Biology of Actinomycetes' '88, pp. 86-91. Edited by Y. Okami, T. Beppu \& H. Ogawara. Tokyo: Japan Scientific Societies Press.

Romero, J., Liras, P. \& Martín, J. F. (1984). Dissociation of cephamycin and clavulanic acid biosynthesis in Streptomyces clavuligerus. Appl Microbiol Biotechnol 20, 318-325.

Rudner, D. Z., LeDeaux, J. R., Ireton, K. \& Grossman, A. D. (1991). The spoOK locus of Bacillus subtilis is homologous to the oligopeptide permease locus and is required for sporulation and competence. J Bacteriol 173, 1388-1398.

Stutzman-Engwall, K. J., Otten, S. L. \& Hutchinson, C. R. (1992). Regulation of secondary metabolism in Streptomyces spp. and overproduction of daunorubicin in Streptomyces peucetius. J Bacteriol 174, 144-154.

Weatherburn, M. W. (1967). Phenol-hypochlorite reaction for determination of ammonia. Anal Chem 39, 971-974.

Willey, J., Schwedock, J. \& Losick, R. (1993). Multiple extracellular signals govern the production of a morphogenetic protein involved in aerial mycelium formation by Streptomyces coelicolor. Genes Dev 7, 895-903.

Received 5 June 1995; revised 24 October 1995; accepted 5 January 1996. 